\title{
AN INVESTIGATION ON CYTOTOXICITY EFFECT OF PUTRESCINE-SULPHUR ANALOGUES ON BREAST CANCER (MCF-7), HUMAN LUNG ADENOCARCINOMA (A549) AND COLORECTAL CANCER (HCT-8) CELL LINES
}

Norsuhana Halim ${ }^{1}$, Radiah Abdul Ghani ${ }^{1}$, Adzly Hairee Sahabudin ${ }^{1}$ and Fiona How Ni Fong $^{1}$

${ }^{1}$ International Islamic University Malaysia, Kuantan, Pahang.

Presenter: Norsuhana Halim, suhanahalim93@gmail.com

Introduction: Cancer is one of the global health problems that has a detrimental effect to a person's life. However, chemotherapeutic agents success are subject to the side effects due to lack of specificity in the drug delivery system to cancer cells and an increase risk of systemic toxicity to the normal cells. Polyamine transport system (PTS) is one of the potential pathways for transporting anticancer agent into specific cancer cells. This is due to the upregulation of PTS in cancer cells compared to normal cells for the proliferation activity. The aim of this study was to investigate the cytotoxicity effect of putrescine-sulphur analogues type 1 (PSA-1) and type 2 (PSA-2) on human lung adenocarcinoma cells (A549), human colorectal adenocarcinoma cells (HCT-8) and human breast adenocarcinoma cell (MCF-7).

Materials and method: The cytotoxicity effect of newly synthesized PSA-1 and PSA-2 were evaluated on selected cancer cells; MCF-7, A549 and HCT-8 cell lines. The halfmaximal inhibitory concentration $\left(\mathrm{IC}_{50}\right)$ obtained from tetrazolium bromide $(\mathrm{MTT})$ assay was derived from the dose-response graph for all cell lines.

Results: PSA-2 elicited cytotoxicity effect, eventhough the $\mathrm{IC}_{50}$ values were not potent with $\mathrm{IC}_{50}$ of $5.4 \mathrm{mM}, 5.2 \mathrm{mM}$ and $7.0 \mathrm{mM}$ for MCF-7/48h, A549/48h and HCT-8/48h, respectively. The PSA-1 compound exhibited cytotoxicity effect in all cell lines, however, the compound failed to induce anti-proliferation at the concentration of $3 \mathrm{mM}$ and above. The cytotoxicity of PSA-2 compound against MCF-7 cell lines showed higher potency compared to A549 and HCT-8 cell lines.

Conclusion: It was suggested that PSA-2 compound was able to exert cytotoxicity effect against selected cancer cells, in low potency and is deemed for further investigation to increase its effectiveness against specific cancer cells. 